\title{
THE EARLY OPERATIONS FOR MITRAL STENOSIS
}

\author{
BY \\ MAURICE CAMPBELL \\ From Guy's Hospital, and the Institute of Cardiology, London W.1
}

Received January 19, 1965

The recent death of Sir Henry Souttar and re-reading his paper on his operation for mitral stenosis (Souttar, 1925) has made me wonder again why there was such a long interval after these first attempts in 1922-26 before the successes in 1948-50.

In 1922, Allen and Graham of St. Louis reported an extensive series of operations on dogs that were important in two ways. First because the valve that was to be divided could be seen through a cardioscope. Secondly because they concluded that the approach to the mitral valve through the left atrial appendage was the best and safest method, and that this was applicable to man.

In 1923, Cutler and Levine of Boston reported the first operation for mitral stenosis. The girl had been in hospital for eight months with severe hæmoptyses and was certainly improved for she lived for four years, though with several re-admissions.

In 1924, Cutler, Levine, and Beck gave a much fuller account of the subject. They had prepared for the operation with careful work on animals, so that they felt at home with entering the heart and handling it, but had not been able to practise the division of a stenosed mitral valve. Though they do not seem to have had special difficulties with the ventricular approach, it was probably unfortunate that they decided to use this rather than the left atrial approach. They gave several theoretical reasons for their choice, but none based on experimental work. They reported three more patients operated on in the same way, but all had died within the first few days. In the fourth and all later patients they used a valvulotome that cut a hole in the valve and must have produced or increased mitral regurgitation.

Also in 1924, Allen reported much more fully on his experimental work in dogs. It was in this year or late in 1923 that he carried out his only operation for mitral stenosis. The woman, aged 32 , had a stormy operation and died before he had been able to cut the valve. The only account of this case I have found is in Cutler and Beck (1929). In a later paper, Allen and Barker (1926) proved with continuous electrocardiograms in dogs that the ventricular approach often produced paroxysmal ventricular tachycardia and sometimes ventricular fibrillation, while the atrial approach rarely caused any significant arrhythmia.

In 1925, Souttar of London reported a successful operation on a girl aged 15, a patient of his medical colleague Dr. Otto Leyton. He followed Allen in his approach through the left atrial appendage and commented on the relative ease of handling the heart and, in spite of some hæmorrhage, on the relative smoothness of the operation, which may have been due to the skill of John Challis, his young anæsthetist at the London Hospital. The mitral orifice admitted his finger so he decided not to increase its size and contented himself with breaking down the adhesions that tethered the cusps, since he did not wish to increase the mitral regurgitation. He felt this regurgitation and in later life described it as like the jet of a fire-hose playing on his finger. He wrote "I felt an appreciation of the mechanical reality of stenosis and regurgitation which I never before possessed" and "the method of digital exploration through the auricular appendage can not be 670 
surpassed for simplicity and directness." His patient lived for seven years but was not much improved.

In 1926, Pribram in Germany operated on one more patient, using the same approach, but she died from pneumonia six days later.

In 1929, Cutler and Beck summarized the results of the operations and reported on the necropsy of their first patient, who had lived for four years. Each of the other six on whom they had performed an operation had died at or soon after it. They hoped that their experience would prove of use in the future, in spite of their great disappointments. They had made the most sustained effort, but had used the more dangerous ventricular approach and a valvulotome that was almost certain to increase mitral regurgitation.

Only two patients had survived. At the necropsy of the patient of Cutler and Levine, four years after the operation, the mitral opening had been enlarged and the scar where the valve had been cut could be seen. There was, however, still some stenosis and some regurgitation-probably more than before, since the systolic murmer had become louder after the operation. This development of a systolic murmur had been found in most of the experiments in dogs.

A photograph of the heart and mitral valve of Souttar's patient, taken at her necropsy seven years after the operation, has been published in his Schorstein Memorial Lecture by William Evans (1961). Clearly from this and the accounts, there was only slight stenosis and dominant mitral regurgitation. It is, therefore, not surprising that there was little change in Souttar's patient and no dramatic improvement in the patient of Cutler and Levine.

Souttar seems to have expressed most clearly the importance of not producing or increasing mitral regurgitation. I have found no clear statement that the valves should be divided at the commissures where they had become adherent. When a knife was used blindly or with poor vision through a cardioscope it would not have been easy; but if the finger was used the splitting would probably have taken place at this site.

Looking back, it is surprising that Allen after all his preparatory work on dogs and only one death, and Souttar after his one operation, at which he had done all that was desirable in the case presented to him, were not asked to operate on other patients with mitral stenosis.

There are three earlier papers that perhaps deserve a short mention. As early as 1902 Lauder Brunton had suggested that with the advances of surgery it should soon be possible to relieve mitral stenosis by surgical methods. He had done no more than show that it was possible to cut the valve in the post-mortem room; and though he suggested that the commissures were the ideal site for the division, he had found it easier to cut the valve itself. A leading article the next week was critical and not encouraging. Lane (1902) wrote that he had suggested such an operation to Dr. L. E. Shaw some time before, but no patient had been forthcoming.

Secondly, Doyen (1913) of Paris attempted to cut the pulmonary valve for stenosis, using an approach through the right ventricle. The patient died during the operation, and had pulmonary infundibular stenosis and a ventricular septal defect.

Thirdly, Tuffier (1914), also of Paris, considered doing the same thing for aortic stenosis, but decided to dilate the valve with his finger, which he introduced by invaginating the wall of the aorta. He thought he had succeeded, but there was no great improvement though the patient lived for several years.

Earlier experimental work on animals was reviewed by Allen (1924) and by Cutler et al. (1924), but their own work was much more significant for the ultimate success.

\section{Subsequent Reflections of a Physician}

Though several of the surgeons emphasized the relative ease with which the heart could be handled, there had been a heavy mortality of 80 per cent. This, however, has not been a bar to the successful development of some other operations. Probably the absence of dramatic improvement in the two survivors had a greater effect at the time.

Many later workers were inclined to attribute their success and the early failures to the great advances that had taken place in thoracic surgery and anæsthesia, in the use of antibiotics, and in 
the general care of patients during and after operations (e.g. Baker, Brock, and Campbell, 1950). No doubt these were important, but there were other more important reasons that must be laid at the door of the physicians. Though the essential effects of mitral stenosis and regurgitation had been understood for a long time (Osler, 1912) and though Gallavardin (1921) had written his first paper on the effects of tight mitral stenosis, there was no general appreciation of the importance of severe stenosis.

Mackenzie and Orr (1923) wrote, "In these cases there are other factors present in addition to the mitral stenosis. The muscle substance is not infrequently damaged and then heart failure is readily induced." They went on to speak of the important part played by the development of atrial fibrillation.

Carey Coombs (1924) in his brilliant chapter on the course and prognosis of rheumatic heart disease did not distinguish a group in which the obstruction of mitral stenosis was the important feature. He wrote "it seems logical to regard every case of mitral stenosis as one of advanced cardiac rheumatism"; and of Cutler and Levine's case "the operation can never become a general method of treatment for a disease of which the mitral lesion is only one factor."

Up to the time of his death, Lewis (1946) still wrote about surgical treatment as follows: "I think it will continue to fail, not only because the interference is too drastic, but because the attempt is based upon what, usually at all events, is an erroneous idea, namely that the valve is the chief source of trouble." He argued with some experimental support that the obstruction produced at the mitral valve could not be enough to produce the effects that were found; but he could not then take into account the effects of the resulting pulmonary vascular resistance. I have quoted from these three authors because of my great admiration for them and their work.

Modern cardiology was only just starting and two of its first new principles, which have saved thousands from a life of invalidism, were not helpful to the operation. These were that the state of the heart muscle was of overriding importance; and that mitral regurgitation was much less common than had been thought and was not to be diagnosed in everyone with a systolic murmur. As happens so often in medicine, and in other aspects of life, the pendulum swung too far. The obstruction caused by stenosis was almost forgotton, so that the physicians were not enthusiastic about the operation. The importance or even the presence of mitral regurgitation was often overlooked, and a correct estimate of the relative importance of mitral stenosis and regurgitation was quite beyond them.

The operations made little impact at the time. They were not a subject discussed at many meetings; and to me as a medical registrar, they did not seem as interesting or as important as the introduction of mercurial diuretics (1920) and of quinidine (1921). Even in 1929 in Recent Advances in Cardiology, East and Bain had little to say about mitral stenosis and nothing about its surgical treatment. The book is dominated by the new discoveries about cardiac infarction, electrocardiography, the radiology of the heart, and treatment with digitalis.

Two new discoveries of about this time gradually helped to bring about a more favourable atmosphere-first, that atrial fibrillation could often be reverted to normal rhythm by the use of quinidine, and secondly that heart failure due to hyperthyroidism could be abolished by surgical treatment of the thyroid. These gradually led the younger physicians to less pessimism about heart failure and encouraged the hope that the heart might yet improve in its function and capacity if other handicaps could be removed. I often spoke of this in my lectures but it was a long time before anyone learnt to think of a persistent ductus or of mitral stenosis as one of the handicaps that might be removed. Even when Russell Brock (as he then was) suggested this to me, my first thought was of the funnel-shaped mitral valves I had seen in the museum and I suggested that pulmonary stenosis would be much easier to deal with. Almost from his first interest in thoracic surgery, Brock was impressed by the ease of the atrial approach and hoped for an opportunity to put it to use: probably experience with war wounds of the heart encouraged him and the other surgeons involved to press forward with operations on the mitral valve.

The knowledge about the structural changes in the lungs in mitral stenosis was greatly extended by 
Parker and Weiss (1936); and another paper by Gallavardin (1934) and one by Bramwell and Morgan Jones (1944) made physicians more aware of the gravity of tight mitral stenosis and of how a left atrium struggling against this obstruction, especially during pregnancy, could suddenly fail with consequent acute pulmonary odema. And this could happen when there was no general enlargement of the heart and when there had been no warning of failure in the patient's previous activity.

Though Mackenzie's teaching about the importance of the heart muscle was not forgotten, better understanding of the importance of mitral regurgitation and some progress in diagnosing the relative degrees of mitral stenosis and regurgitation gradually developed, though still far behind the more accurate appreciation that has been reached today.

\section{CONCLUSION}

Looking back with the experience gained from successful mitral valvotomy, the main reasons for the failure of the early attempts seem to be the general underestimate at that time of the severe burden that tight mitral stenosis placed on the heart, and the failure to judge correctly the degrees of stenosis and regurgitation.

Allen and Graham deserve the credit for pioneering the left atrial approach to operate, mostly in animals but in one woman, on a valve that could be seen through a cardioscope; Cutler and Levine for planning and carrying out the first partly successful operation on a young woman; and Souttar for his use of the finger to estimate the amount of stenosis and regurgitation, with direct vision of the cavity. For these successes, they can be remembered as the early pioneers of the successful operations of today, though at the time they must have been greatly disheartened by their results.

I should like to thank Dr. Samuel Levine for replying to my questions, Sir Russell Brock for his valuable comments, and Dr. Arthur Hollman for drawing my attention to the quotation from Sir Thomas Lewis.

\section{REFERENCES}

Allen, D. S. (1924). Intracardiac surgery. Arch. Surg., 8, 317.
, and Barker, P. S. (1926). Surgery of the mitral valve: an experimental electrocardiographic study. Amer. Heart J., 1, 693.

$\longrightarrow$, and Graham, E. A. (1922). Intracardiac surgery-a new method. J. Amer. med. Ass., 79, 1028.

Baker, C., Brock, R. C., and Campbell, M. (1950). Valvulotomy for mitral stenosis; report of six successful cases. Brit. med. J., 1, 1283.

Bramwell, C., and Jones, A. M. (1944). Acute left auricular failure. Brit. Heart J., 6, 129

Brunton, Lauder (1902). Preliminary note on the possibility of treating mitral stenosis by surgical methods. Lancet, 1, 352.

Coombs, C. F. (1924). Rheumatic Heart Disease. John Wright, Bristol.

Cutler, E. C., and Beck, C. S. (1929). Present status of the surgical procedures in chronic valvular disease of the heart; final report of all surgical cases. Arch. Surg., 18, 403.

—, and Levine S. A. (1923). Cardiotomy and valvulotomy for mitral stenosis. Boston med. surg. J., 188, 1023.

-, arch and Beck, C. S. (1924). The surgical treatment of mitral stenosis: experimental and clinical studies. Arch. Surg., 9, 689.

Doyen, E. (1913). Chirurgie des malformations congénitales ou acquises du coeur. Presse méd., 21, 860.

East, C. F. T., and Bain, C. W. C. (1929). Recent Advances in Cardiology. Churchill, London.

Evans, W. (1961). Cardiology at the London Hospital. Lond. Hosp. Gaz., 64, Clin. sci. Suppl. to no. 4.

Gallavardin, L. (1921). De l'oedème pulmonaire aigu dans les cardiopathies valvulaires endocardiques en dehors de la gravidité: insuffisance ventriculaire et insuffisance auriculaire gauches. Arch. Mal. Cour, 14, 262.

- (1934). Le rétrécissement mitral œéémateux. J. Méd. Lyon, 15, 609.

Lane, W. Arbuthnot (1902). Correspondence in Lancet, 1, 547.

Lewis, Sir Thomas (1946). Diseases of the Heart, 4th ed., pp. 154 and 159. Macmillan, London.

Mackenzie, Sir James, and Orr, J. (1923). Principles of Diagnosis and Treatment in Heart Affections, 2nd ed. Henry Frowde and Hodder \& Stoughton, London.

Osler, Sir William (1912). The Principles and Practice of Medicine, 8th ed. D. Appleton, New York and London.

Parker, F., Jr., and Weiss, S. (1936. The nature and significance of the structural changes in the lungs in mitral stenosis. Amer. J. Path., 12, 573.

Pribram, B. O. (1926). Die operative Behandlung der Mitralstenose. Arch. klin. Chir., 142, 458.

Souttar, H. S. (1925). The surgical treatment of mitral stenosis. Brit. med. J., 2, 603.

Tuffer, T. (1914). État actuel de la chirurgie intrathoracique. Trans. 17th int. Congr. Med., London. Sect. 7, Surgery, Pt. 2, p. 247. Oxford University Press, London. 